\title{
Phagocytosis Inhibition
}

National Cancer Institute

\section{Source}

National Cancer Institute. Phagocytosis Inhibition. NCI Thesaurus. Code C40806.

Phagocytosis Inhibition involves interference with, or restraint of, the process of endocytosis of particulate material by phagocytes, such as microorganisms or cellular fragments and debris, into membranous phagosomes that fuse with lysosmes and result in digestion of the ingested material; an important defense against infection. $(\mathrm{NCl})$ 